\title{
In vitro-induced antibody production in chronic hepatitis $C$ virus infection
}

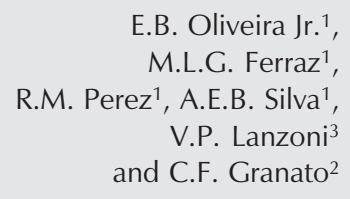

E.B. Oliveira Jr. ${ }^{1}$,

M.L.G. Ferraz ${ }^{1}$, R.M. Perez ${ }^{1}$, A.E.B. Silva ${ }^{1}$,

V.P. Lanzoni ${ }^{3}$

and C.F. Granato ${ }^{2}$

Divisões de ${ }^{1}$ Gastroenterologia, and ${ }^{2}$ Doenças Infecciosas e Parasitárias, and ${ }^{3}$ Departamento de Patologia, Escola Paulista de Medicina,

Universidade Federal de São Paulo, São Paulo, SP, Brasil

\section{Correspondence}

M.L.G. Ferraz

Rua Machado Bittencourt, 413

Apto. 81

04044-001 São Paulo, SP

Brasil

Publication supported by FAPESP.

.....................

Received April 3, 2002

Accepted November 14, 2002

\section{Abstract}

The objectives of the present study were to assess the in vitro-induced anti-hepatitis $\mathrm{C}$ virus (HCV) antibody production (IVIAP) in relation to the clinical, biochemical, virologic and histologic variables of patients with HCV infection. The study included 57 patients $(60 \%$ males) with HCV infection (anti-HCV and HCV-RNA positive). Alanine aminotransferase (ALT) was elevated in $89 \%$ of the patients. Mean viral load was 542,241 copies/ml and histology of the liver showed chronic hepatitis in 27/52 (52\%) and cirrhosis in 11/52 (21\%) patients. IVIAP levels were determined by immunoenzymatic assay at median absorbance of 0.781 at $450 \mathrm{~nm}$. IVIAP was negative in $14 \%$ of the patients. When groups with IVIAP levels above and below the median were compared, high IVIAP levels were associated with the male sex, elevated ALT levels and more advanced disease stage. After logistic regression analysis, advanced histologic damage to the liver remained as the only independent variable associated with elevated IVIAP levels. Using a receiver operator characteristic curve, the best cut-off level for IVIAP was established $(=1.540)$, with $71 \%$ sensitivity and $94 \%$ specificity for the detection of more advanced disease stages (grades 3 and 4). These findings are consistent with the participation of immunological mechanisms in the genesis of the hepatic lesions induced by HCV and indicate that the IVIAP test may be useful as a noninvasive marker of liver damage either alone or in combination with other markers.

\section{Introduction}

Infection with hepatitis $\mathrm{C}$ virus (HCV) is widely distributed, with an estimated number of 170 million chronically infected individuals worldwide (1). The diagnostic approach to chronically $\mathrm{HCV}$-infected patients includes serologic and molecular biology tests and especially histologic hepatic evaluation, which permit an adequate characterization
Key words

- Hepatitis C

- In vitro-induced antibody production

- IVIAP

- Hepatitis C virus-RNA

- Liver biopsy

- Anti-HCV antibodies 
sive manner.

It has been demonstrated for several viral diseases that viral replication is related to in vitro antibody secretion $(2,3)$. Based on this phenomenon, in 1994 Ducos et al. (4) described a diagnostic test for hepatitis $\mathrm{C}$ which was based on the relation between activation of the immune system by viral antigens and specific in vitro antibody secretion by peripheral blood lymphocytes. The objective of the method was to differentiate between carriers of active infection with viremia and subjects with previous infection in the presence of an anti-HCV-positive test. In this test, spontaneous in vitro antibody production was observed after 8 days of incubation in culture. When in vitro antibody production results were compared to $\mathrm{HCV}$-RNA results, $100 \%$ agreement was found, suggesting that active secretion of anti-HCV antibodies by lymphocytes was related to viral replication.

Variations of this method have been tested for the diagnosis of other viral infections such as cytomegalovirus $(5,6)$ and HIV (3), with a good correlation demonstrable between spontaneous antibody secretion and viremia. On the basis of these findings, Caterino-de-Araujo et al. (7) developed a new laboratory method based on in vitro antibody production, this time induced by specific HIV antigens (in vitro-induced antibody production, IVIAP), which permitted obtaining more rapid results at the end of 24 $\mathrm{h}$ of observation. The cited study showed that the results of the test agreed with those of HIV-RNA, with 91\% sensitivity and 96\% specificity, in addition to the fact that the test was rapid, practical and of low cost.

The use of IVIAP in hepatitis $\mathrm{C}$ was evaluated only in patients under treatment with interferon in a study which demonstrated that a favorable response to treatment was related to the reduction of antibody production in vitro (Arrais TC and Granato $\mathrm{CF}$, unpublished results). However, there are no studies in the literature in which IVIAP behavior was studied in relation to epidemiologic or virologic variables or to different histologic stages of the disease in patients with chronic hepatitis $\mathrm{C}$ infection.

The objectives of the present study were to assess the efficacy of the IVIAP test in patients with chronic HCV infection not submitted to treatment, by analyzing the results of IVIAP during the different phases of the disease and its relation to different aspects of $\mathrm{HCV}$ infection.

\section{Patients and Methods}

\section{Patients}

The study was conducted from October 1999 to February 2001 at the Hepatitis Outpatient Clinic of the Gastroenterology Division, Universidade Federal de São Paulo, on selected patients with chronic hepatitis $\mathrm{C}$ characterized by the presence of anti-HCV antibodies (IMX ${ }^{\circledR}$, Abbott Laboratories, Chicago, IL, USA) and HCV-RNA positivity (Amplicor ${ }^{\circledR}$ 2.1.1, Roche Diagnostics Corporation, Indianapolis, IN, USA), who had been submitted to a liver biopsy.

After approval of the study by the local Ethics Committee and informed consent from the subjects, patients of both sexes ranging in age from 18 to 70 years were included in the study. Patients co-infected with HBV and/or HIV, patients under current treatment or previously treated for hepatitis $\mathrm{C}$, patients with chronic renal failure or patients consuming more than $40 \mathrm{~g}$ ethanol/day were excluded.

The epidemiologic, biochemical, virologic and histologic characteristics of the disease were related to the levels of IVIAP.

\section{Laboratory methods}

Biochemical evaluation. Alanine aminotransferase (ALT) and aspartate aminotransferase were determined by an automated kinetic method (Cobas Mira, Roche 
Diagnostics, Basel, Switzerland). HCV-RNA levels were determined using Amplicor ${ }^{\circledR}$ Monitor kits (Roche Diagnostics). The limit of sensitivity of the method reported by the manufacturer is 500 copies $/ \mathrm{ml}$.

In vitro-induced antibody production. The IVIAP test was based on the preparation of peripheral blood lymphocytes in culture with incubation on microtiter plates sensitized with the HCV antigen (Diasorin ${ }^{\circledR}$, Diasorin Inc., Stillwater, MN, USA), followed by quantification of specific antibody production in vitro. Lymphocytes were obtained from peripheral blood collected into heparinized tubes by separation on Ficoll Hypaque $^{\circledR}$ (Pharmacia, Uppsala, Sweden). The lymphocyte suspension was diluted with RPMI medium containing $10 \%$ fetal calf serum, with the concentration adjusted to $3 \mathrm{x}$ $10^{6}$ cells $/ \mathrm{ml}$. Two hundred microliters of this cell suspension was added to the orifices of the microplates, sensitized with HCV antigen (recombinants $\mathrm{C} 22$ and C33 and synthetic NS4 and NS5) and incubated for 18$24 \mathrm{~h}$ at $37^{\circ} \mathrm{C}$ in the presence of $5 \% \mathrm{CO}_{2}$. On the following day, the plates were washed with $0.05 \%$ Tween 20 -PBS and $100 \mu 1$ of the conjugate (goat IgG anti-human $\operatorname{IgG}$ ) was pipetted into the orifices of the microplate. After incubation for $1 \mathrm{~h}$ at $37^{\circ} \mathrm{C}$ and washing three times, the substrate for the color reaction was added. The plates were read $30 \mathrm{~min}$ later by spectrophotometry at $450 \mathrm{~nm}$. A positive and a negative control (known standard sera, provided by the Diasorin kit) were used and the cut-off was determined in each test battery. The cut-off was calculated for each assay and corresponded to twice the absorbance value for the negative control. Samples whose readings were above this cut-off value were considered to be positive. For the study of the relation between IVIAP levels and variables of interest the results of the tests were divided into two groups: a) IVIAP values above the median obtained for the sample ("high" IVIAP), and b) IVIAP values below the median ("low" IVIAP).
Histologic evaluation. A liver biopsy was performed 6 months before or after IVIAP determination. The fragments of liver tissue obtained by percutaneous biopsy with a Tru$\mathrm{Cut}^{\circledR}$ needle were fixed in 10\% formalin and stained with hematoxylin-eosin, Masson trichrome, and Prussian blue (Perls method) and by impregnation of reticular fibers with silver (Gomori method). All the slides of the liver biopsy were analyzed by a single pathologist who evaluated necroinflammatory portal/periportal activity and staging using the semiquantification criteria proposed by Ludwig (8) and Desmet et al. (9) for the classification of chronic hepatitis.

\section{Statistical analysis}

Data were analyzed statistically using the SPSS program, version 10.0 for Windows. The quantitative variables are reported as mean, standard deviation and median and the qualitative variables as absolute $(\mathrm{N})$ and relative (\%) frequency. Categorical variables were analyzed by the chi-square test or Fisher's exact test when indicated.

The presence of a possible correlation between IVIAP levels and viral load was determined by the Spearman correlation coefficient.

Variables showing $\mathrm{P}<0.25$ significance were submitted to logistic regression analysis for the identification of variables independently associated with elevated IVIAP levels. The receiver operator characteristic (ROC) curve was used to identify the best IVIAP value for the detection of more advanced staging $(E \geq 3)$. On the basis of this value, we identified the best sensitivity and specificity value for IVIAP for the diagnosis of more advanced staging $(E \geq 3)$.

The level of significance was set at $\mathrm{P}<0.05$ for all analyses.

\section{Results}

A total of 127 anti-HCV RNA-positive 
patients referred to the Hepatitis Outpatient Clinic of Universidade Federal de São Paulo were evaluated from October 1999 to February 2001 and 57 of them were included in the study on the basis of the inclusion and exclusion criteria.

\begin{tabular}{|c|c|}
\hline $\operatorname{Sex}(M / F)$ & $34 / 23$ \\
\hline Age (years) & $49 \pm 13$ \\
\hline Parenteral risk factor (\%) & $29(51 \%)$ \\
\hline History of blood transfusion & $23(40 \%)$ \\
\hline Intravenous drug use & $6(11 \%)$ \\
\hline Elevated ALT (\%) & $51(89 \%)$ \\
\hline ALT ( $x$ UNL) & $2.7 \pm 2.4$ \\
\hline AST ( $x$ UNL) & $1.8 \pm 1.1$ \\
\hline \multicolumn{2}{|l|}{ HCV viral load } \\
\hline \multicolumn{2}{|l|}{ No. of patients with HCV-RNA } \\
\hline$>2 \times 10^{6}$ copies $/ \mathrm{ml}$ & $15(25 \%)$ \\
\hline Mean (copies/ml) & 542,241 \\
\hline IVIAP (median) & 0.781 \\
\hline \multicolumn{2}{|l|}{ IVIAP } \\
\hline Positive (\%) & $49(86 \%)$ \\
\hline Negative (\%) & $8(14 \%)$ \\
\hline
\end{tabular}

Data are reported as means $\pm S D . M=$ male; $F=$ female; $U N L$ = upper normal limit; $A L T=$ alanine aminotransferase; $A S T=$ aspartate aminotransferase; $\mathrm{HCV}=$ hepatitis $\mathrm{C}$ virus; IVIAP = in vitro-induced antibody production.

Table 2. Comparison of patients with high and low in vitroinduced antibody production (IVIAP) (total $\mathrm{N}=57$ ).

\begin{tabular}{lcc}
\hline & $\begin{array}{c}\text { High IVIAP } \\
(\mathrm{N}=29)\end{array}$ & $\begin{array}{c}\text { Low IVIAP } \\
(\mathrm{N}=28)\end{array}$ \\
\hline Male sex & $21(72)$ & $13(46)^{*}$ \\
Age $\geq 49$ years & $15(51)$ & $17(61)$ \\
Parenteral risk factor & $15(51)$ & $14(50)$ \\
Elevated ALT & $29(100)$ & $22(79)^{*}$ \\
Elevated AST & $23(79)$ & $19(68)$ \\
Viral load $\geq 542,241$ copies/ml & $15(52)$ & $14(50)$ \\
Staging $\geq 3$ & $12 / 24(50)$ & $5 / 25(20)^{*}$ \\
Portal/periportal activity $\geq 3$ & $9 / 25(36)$ & $6 / 27(22)$ \\
\hline
\end{tabular}

High and low refer to the median ELISA absorbance value at $450 \mathrm{~nm}: 0.781$. Percent values are given in parentheses. ALT, AST = alanine and aspartate aminotransferase, respectively. ${ }^{*} \mathrm{P}<0.05$ compared to high IVIAP (chi-square test).
Of these 57 patients, $34(60 \%)$ were males and $23(40 \%)$ females, ranging in age from 18 to 70 years (mean \pm SD: $49 \pm 13$ years). Twenty-three patients $(40 \%)$ had received blood transfusion and $6(11 \%)$ were intravenous drug users. Twenty-nine of the 57 patients $(51 \%)$ presented a parenteral risk factor for HCV acquisition (Table 1).

ALT levels were abnormal in 51 patients (89\%), with a mean concentration of $2.7 \mathrm{x}$ the upper normal limit (UNL). Mean viral load was 542,241 copies/ml (Table 1) and hepatic histology showed the presence of minimal changes in $14 / 52$ patients (27\%), chronic hepatitis in 27/52 (52\%), and cirrhosis in 11/52 (21\%). In five patients the fragments were not adequate for histologic analysis.

IVIAP levels determined in peripheral blood lymphocytes incubated on ELISA plates sensitized with HCV antigen showed a median absorbance of 0.781 . IVIAP was negative in 8 patients $(14 \%)$, i.e., below the cut-off established for the test (Table 1).

Analysis by the Spearman correlation coefficient showed no correlation between IVIAP levels and viral load $(\mathrm{r}=0.08, \mathrm{P}=$ $0.55)$.

Comparison of IVIAP levels above and below the median with the epidemiologic, biochemical, virologic and histologic variables demonstrated that elevated IVIAP levels were significantly associated with male sex, ALT levels above normal, and more advanced disease stages (grades 3 and 4; Table 2).

After logistic regression analysis, more advanced staging remained as the only variable independently associated with elevated antibody production in vitro (Table 3 ). For this variable, the best cut-off value for IVIAP $(=1.540)$ was established by means of a ROC curve (Figure 1), with $71 \%$ sensitivity and $94 \%$ specificity for the test in the detection of more advanced disease stages. The positive predictive value was $86 \%$ and the negative predictive value was $86 \%$. 


\section{Discussion}

In patients infected with $\mathrm{HCV}$, active secretion of anti-HCV antibodies by peripheral blood lymphocytes reflects the interaction of the immune system with HCV antigens and seems to be related to HCV replication and to hepatic dysfunction (4).

Measurement of IVIAP reflects persistent antigenic stimulation of the immune system, possibly induced by viral replication. The IVIAP test used in combination with quantitative HCV-RNA determination may eventually provide supplementary information about disease activity and about response to treatment, thus being a candidate for use as a new auxiliary laboratory test for the diagnosis and monitoring of $\mathrm{HCV}$ infection.

The objective of the present study was to evaluate the relation between IVIAP and epidemiologic, virologic and histologic variables and to consider the possible applicability of the test as a noninvasive method for the evaluation of $\mathrm{HCV}$-induced hepatic damage.

The IVIAP test was positive in 49 patients $(86 \%)$ and negative in $8(14 \%)$. Although patients with absent viremia (HCVRNA negative) were not studied to determine the specificity of the test in detecting viremia, we conclude that the sensitivity of the method for the characterization of viremia was $86 \%$. In a study of HCV-infected patients submitted to antiviral treatment, Arrais and Granato (Arrais TC and Granato $\mathrm{CF}$, unpublished results) obtained $88.2 \%$ sensitivity, a value quite similar to the one detected in the present study. In a study of in vitro antibody production in patients with chronic C virus infection, Ducos et al. (4), in 1994, also observed a good correlation between the secretion of anti-HCV antibodies and viremia, with $64 \%$ sensitivity and $100 \%$ specificity.

For patients with active disease and a negative IVIAP test (only 8 in the present

study), we may assume a low production of induced antibodies that did not permit their detection by the methodology employed. The mean absorbance obtained for the IVIAP levels of the 57 patients studied was 1.056 , with a median of 0.781 and a standard deviation of \pm 0.868 . Arrais and Granato (Arrais TC and Granato CF, unpublished results) detected mean pretreatment IVIAP levels of 1.200 , ranging from 0.780 to 1.610 , and therefore closely similar to those detected in the present study.

In the present study we analyzed the association between IVIAP levels and epidemiologic, biochemical, virologic and histologic variables. For this purpose, the 57 pa-

Table 3. Logistic regression analysis.

\begin{tabular}{lc}
\hline \multicolumn{2}{l}{ Initial model } \\
\hline Variable & $P$ \\
\hline Sex & 0.046 \\
ALT & 0.010 \\
Staging & 0.027
\end{tabular}

Final model

\begin{tabular}{cccc}
\hline & $P$ & OR & $95 \% \mathrm{Cl}$ \\
\hline Staging & $<0.001$ & 35.98 & $6.12-211.48$
\end{tabular}

$\mathrm{ALT}$ = alanine aminotransferase; OR = odds ratio; $\mathrm{Cl}=$ confidence interval.

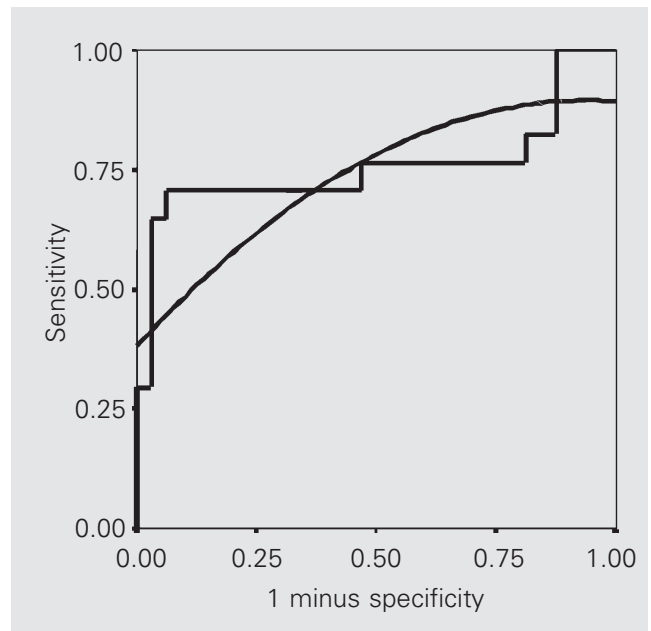

Figure 1. Cut-off point, sensitivity and specificity of in vitroinduced antibody production in the detection of advanced stages (3 and 4) established by a receiver operator characteristic curve. 
tients were divided into two groups according to IVIAP levels, i.e., levels above the median, and levels below the median. The initial bivariate analysis performed showed a statistically significant association between elevated IVIAP levels and the following variables: sex $(\mathrm{P}=0.04)$, high ALT levels $(\mathrm{P}=$ $0.01)$, and more advanced staging $(\mathrm{P}=0.03)$.

Although the occurrence of higher IVIAP levels among males has not been established, this finding in the present study appears to be related to the worse disease course in male patients, as demonstrated by others (10). Indeed, when the logistic regression model was used to evaluate the variables independently associated with more elevated IVIAP levels, more advanced staging was the only variable showing this association. The reason why male patients develop hepatic fibrosis more rapidly and more advanced staging grades is not clear, but appears to be related to other factors such as greater alcohol consumption $(10,11)$, more common among men, or to greater iron accumulation in the liver, which appear to determine a worse histologic evolution among HCV-infected patients (12).

No significant association was observed between IVIAP levels and age or transmission risk factors.

Comparative analysis concerning the biochemical characteristics showed that elevated IVIAP levels were significantly associated with elevated ALT levels (above $1 \times$ UNL) $(P=0.01)$. This suggests that hepatic damage must be related to the immune system which may act not only on the virus, but also on the hepatic parenchyma, causing hepatocellular damage and also being responsible for the pathogenesis of chronic HCV infection. In a study of in vitro antibody production in HCV infection, Ducos et al. (4) also detected a statistically significant association between a positive test and elevated ALT levels $(\mathrm{P}<0.001)$. Similarly, Arrais and Granato also demonstrated similar ALT curves and IVIAP levels during the treatment of hepatitis, i.e., a decrease in ALT levels with decreasing IVIAP levels at 30, 60 and 90 days of treatment (Arrais TC and Granato CF, unpublished results).

After logistic regression analysis, ALT was not independently associated with elevated IVIAP levels, showing that its correlation was probably mediated by structural hepatic damage for which ALT was possibly acting as an indirect marker.

Also, no significant correlation was observed between viral load and IVIAP levels $(\mathrm{P}=0.37)$. The correlation between the presence of viremia and in vitro antibody production seems to be clear, as also demonstrated in other studies $(4,13)$. However, the levels of viral load were not studied in any of these investigations and the dynamic relationship between antibody production and viral clearance is still unknown. The relationship between these variables (viral load and antibody levels) may be modulated by mechanisms used by HCV to avoid the humoral and cellular immune response as the disease progresses to chronic hepatitis. It is possible that the immune response is qualitatively and quantitatively insufficient to destroy all infected cells (14), causing a lack of relation between antibody levels and viral load in chronically infected patients.

With respect to the histologic variables, a statistically significant and independent association was observed between elevated IVIAP levels and more advanced staging $(P=0.03)$. Although the mechanisms that cause increased production of anti-HCV antibodies are not clear, this finding suggests the participation of immune-mediated mechanisms in the pathogenesis of the disease (4), causing a more significant fibrosis progression in patients with higher antibody levels. The higher antibody levels observed could be an epiphenomenon of the immune response elicited mainly by the cellular component and may not have a direct pathogenic role.

With respect to portal/periportal activity, there was no significant difference between 
this histologic variable and high IVIAP levels $(P=0.55)$. Similarly, when analyzing pretreatment hepatic biopsies, Arrais and Granato (Arrais TC and Granato CF, unpublished results) also did not find a significant association between elevated IVIAP levels and portal/periportal activity in 20 patients studied $(\mathrm{P}=0.6)$. They also obtained a significant relationship with staging, as was the case for the present study $(\mathrm{P}=0.04)$, showing that antibody production is somehow associated with an increased rate of fibrosis progression.

Since staging was the only variable that showed independent association with high IVIAP levels, a ROC curve was calculated to determine the cut-off point for IVIAP with the highest sensitivity and specificity for the detection of more advanced staging. With a cut-off point for IVIAP of 1.540 , sensitivity was $71 \%$ and specificity $94 \%$, showing that IVIAP, with this proposed cut-off level, could function as an indirect and noninvasive test for patients who cannot be submitted to a liver biopsy.

The search for noninvasive tests for the evaluation of hepatic damage induced by $\mathrm{HCV}$ has been a constant concern in clinical practice since the patients cannot always be submitted to a liver biopsy due to contraindications, especially coagulation disorders that prevent the procedure. In addition, multiple biopsies are often necessary during followup, increasing patient discomfort and risk.

Thus, several tests have been proposed in an attempt to indirectly evaluate the degrees of derangement of the underlying hepatic structural architecture. Tests such as determination of serum laminin (15), type III procollagen (16), gamma-glutamyltransferase $(17,18)$ and hyaluronic acid (19), among others, have been proposed with this objective, providing sensitivity rates ranging from 34 to $76 \%$ and specificity from 71 to $100 \%$. More recently, the combination of several of these tests has been proposed (20), with a considerable increase in predictive value. Thus, the IVIAP test may contribute to the noninvasive evaluation of histologic hepatic damage, especially of the degree of underlying hepatic fibrosis either separately or in combination with other noninvasive tests, since it showed good positive and negative predictive values.

The IVIAP test, which was used to evaluate the in vitro production of anti-HCV antibodies in patients with chronic HCV infection, showed an association between elevated antibody levels and male sex, elevated ALT level, and more advanced grades of histologic staging. Staging was the only variable showing independent association with high IVIAP levels upon logistic regression analysis. These findings suggest the participation of immunologic mechanisms in the genesis of the hepatic lesions induced by HCV, although a direct pathogenic role of antibodies cannot be proposed on the basis of the present study. Our findings also indicate that the IVIAP test may be useful as a noninvasive marker of histologic hepatic damage either alone or in combination with other markers.

\section{References}

1. Lauer GM \& Walker BD (2001). Hepatitis C virus infection. New England Journal of Medicine, 345: 41-52.

2. Sedgwick JD \& Holt PG (1986). The ELISA-plaque assay for the detection and enumeration of antibody-secreting cells. Journal of Immunological Methods, 87: 37-44.

3. Amadori A, De Rossi A, Giaquinto C, Faulkner-Valle G, Zachello F \& Chieco-Bianchi L (1988). In vitro production of HIV-specific antibody in children at risk of AIDS. Clinical Immunology and Immunopathology, 46: 342-351.
4. Ducos J, Bianchi-Mondain AM, François M, Boisset M, Vendrell JP, Baring F, Serre A \& Larrey D (1994). Hepatitis C virus (HCV) - Specific in vitro antibody secretion by peripheral blood lymphocytes: correlation with progression of disease and HCV-RNA in HCV antibody positive patients. Journal of Clinical Microbiology, 32: 2613-2615.

5. Segondy M, Vendrell JP, Reynes J, Huguet MF, Albat B, Ducos J, Nicolas JC \& Serre A (1990). Cytomegalovirus-specific B cell activation as a potential marker for the diagnosis of cytomegalovirus infection. European Journal of Clinical Microbiology and Infectious 
Diseases, 9: 745-750

6. Vendrell JP, Segondy M, Fournier AM, Huguet MF, Reynes J, Ducos J \& Serre A (1991). Spontaneous in vitro secretion of antibody to cytomegalovirus (CMV) by human peripheral blood mononuclear cells: a new approach to studying the CMV-immune system interaction. Journal of Infectious Diseases, 164: 1-7.

7. Caterino-de-Araujo A, Santos-Fortuna E \& Grumach AS (1991). An alternative method for in vitro production of HIV-specific antibodies. Brazilian Journal of Medical and Biological Research, 24: 797-799.

8. Ludwig J (1993). The nomenclature of chronic active hepatitis: an obituary. Gastroenterology, 105: 274-278.

9. Desmet VJ, Gerber M, Hoofnagle JH, Manns M \& Scheuer P (1994). Classification of chronic hepatitis: diagnosis, grading and staging. Hepatology, 19: 1513-1520.

10. Poynard T, Bedossa P \& Opolon P (1997). Natural history of liver fibrosis progression in patients with chronic hepatitis $\mathrm{C}$. The Obsvirc, Metavir, Clinivir and Dosvirc groups. Lancet, 349: 825-832.

11. Nishigushi S, Kuroki T, Yabusako T, Seki S, Kobayashi K, Monna T, Otani S, Sakurai M, Shikata T \& Yamamoto S (1991). Detection of hepatitis $C$ virus antibodies and hepatitis $C$ virus RNA in patients with alcoholic liver disease. Hepatology, 14: 985-989.

12. Izumi N, Enomoto N, Uchihara M, Murakami T, Ono K, Nogushi O \& Miyake S (1996). Hepatic iron contents and response to interferon- $\alpha$ in patients with chronic hepatitis C. Digestive Diseases and Sciences, 41: 989-994.

13. Lohr HF, Gerken G, Roth M, Weyer S, Schlaak JF, Meyer ZUM \& Buschenfelde KH (1998). The cellular immune response induced in the follow-up of interferon-alpha treated patients with chronic hepatitis C may determine the therapy outcome. Journal of Hepatology, 29: $524-532$.

14. Rehermann B \& Chisari FV (2000). Cell mediated immune response to the hepatitis $\mathrm{C}$ virus. Current Topics in Microbiology and Immunology, 242: 299-325.

15. Popper HE \& Schaffner F (1971). The vocabulary of chronic hepatitis. New England Journal of Medicine, 384: 1154-1157.

16. Teare JP, Sherman D, Greenfield SM, Simpson J, Bray G, Caterra AP, Murray-Lion IM, Peters TJ, Williams R \& Thompson RP (1993). Comparison of serum procollagen III peptide concentrations and PGA index for assessment of hepatic fibrosis. Lancet, 342: 895-898.

17. Jenkins PJ, Cromie SL, Roberts SK, Finch CF \& Dudley FJ (1996). Chronic hepatitis C, alcohol and hepatic fibrosis. Hepatology, 24: 153A (Abstract).

18. Ikeda K, Saitoh S, Suzuki Y, Kobayashi M, Tsubota A, Koida I, Arase Y, Fukuda M, Chayama K, Murashima N \& Kumada H (1998). Disease progression and hepatocellular carcinogenesis in patients with chronic viral hepatitis: a prospective observation of 2215 patients. Journal of Hepatology, 28: 930-938.

19. Lindqvist $U$ (1997). Is serum hyaluronan a helpful tool in the management of patients with liver diseases? Journal of Internal Medicine, 242: 67-71.

20. Imbert-Bismut $F$, Ratziu $V$, Pieroni L, Charlotte F, Benhamou $Y$ \& Poynard T (2001). Biochemical markers of liver fibrosis in patients with hepatitis C virus infection: a prospective study. Lancet, 357: 1069-1075 